\title{
Mineralogy of Graphite from the Graphite-Bearing Schists of Wadi Lawi, South Eastern Desert, Egypt
}

\author{
Ahmed M. Bishady \\ Geology Department, Faculty of Science, Menufiya University, Shebin El-Kom, Mnufiya, Egypt
}

\begin{abstract}
The graphitized schists of Wadi Lawi, South Eastern Desert, Egypt, had been investigated to exhibit the mineralogy of the graphitic material, and its structural state, to reveal its conditions. The graphite included quartz-plagioclase-actinolite-graphite schist and actinolite-talc-chlorite-graphite schist. It occurs as bundles and laths, showing Rmax in oil from 10 to 14. Magnetite is the major associate with graphite or disposed in the groundmass. XRD, DTA patterns, TEM and TMD investigations of separated graphitic material, show that it ranges in its structure from semi-graphite (graphite-d1) to graphite (full-ordered graphite). $\delta^{13} \mathrm{C}(\mathrm{PDB})$ with an average of $-23.06 \%$, in addition, the IR investigations for these graphitic materials indicate their organogenic origin. The present author suggests the possibility that Wadi Lawi graphitic material is related to post-depositional contaminations. XRD and DTA can also declare that the graphitic materials were formed under conditions of greenschist facies in a temperature range of 400 to $600{ }^{\circ} \mathrm{C}$, under a pressure of 4 to $6 \mathrm{kP}$.
\end{abstract}

Key words: Graphite, Wadi Lawi, ophiolites, mineralogy, structural state.

\section{Introduction}

The area of Wadi Lawi in the South Eastern Desert of Egypt is delineated by the Longs: $34^{\circ} 20^{\prime}$ and $34^{\circ} 49^{\prime}$ E. and Lats $24^{\circ} 44^{\prime}$ and $24^{\circ} 47^{\prime} \mathrm{N}$ (Fig. 1). The graphite-bearing schists of the studied area are included in the mélange matrix, which constitute a member of Wadi Ghadir ophiolite sequence, previously studied by several authors [1-5].

Several graphite occurrences in the Eastern Desert of Egypt were recorded [6-10]. Further Hilmy (1960) and Sabet [11] gave brief descriptions of some graphite occurrences in Egypt, mostly associated with chlorite-actinolite and psammo-pelitic biotite schists. Partial chemical analyses were given by Anwar and Kotb (1966) [12].

El Hinnawi et al. (1973) [13] gave a detailed mineralogical and geochemical study of some graphite-bearing schists in the Central Eastern Desert of Egypt. They concluded that the graphite-bearing schists were mostly derived from politic and

Corresponding author: Ahmed Bishady, professor, research fields: mineralogy and petrology. calc-pssamo-pelitic sediments, and that the graphite in these schists was derived mainly from biogenic material that associated the sediments through metamorphism processes.

The present work aims to portray the mineralogy of the graphite associated with the ophiolite matrix schists of Wadi Lawi, and its structural state revealing its formation conditions.

\subsection{Petrography of the Graphite-Bearing Schists}

The graphitized schists of Wadi Lawi are associated mainly with the actinolite-bearing schists of the mélange matrix. They are highly friable and occur in a patchy form occasionally enclosing white powdered talc rock, which indicates the effect of metasomatism in the area of graphitization. The graphite-bearing schists exhibit petrographically a well defined schistosity, and can be distinguished into two varieties.

\subsection{Quartz-Plagioclase-Actinolite-Graphite Schists}

In this variety quartz presents as elongated xenoblastic grains, reaching up to $0.88 \mathrm{~mm}$ across. Occasionally, quartz veinlets traverse the graphitic 


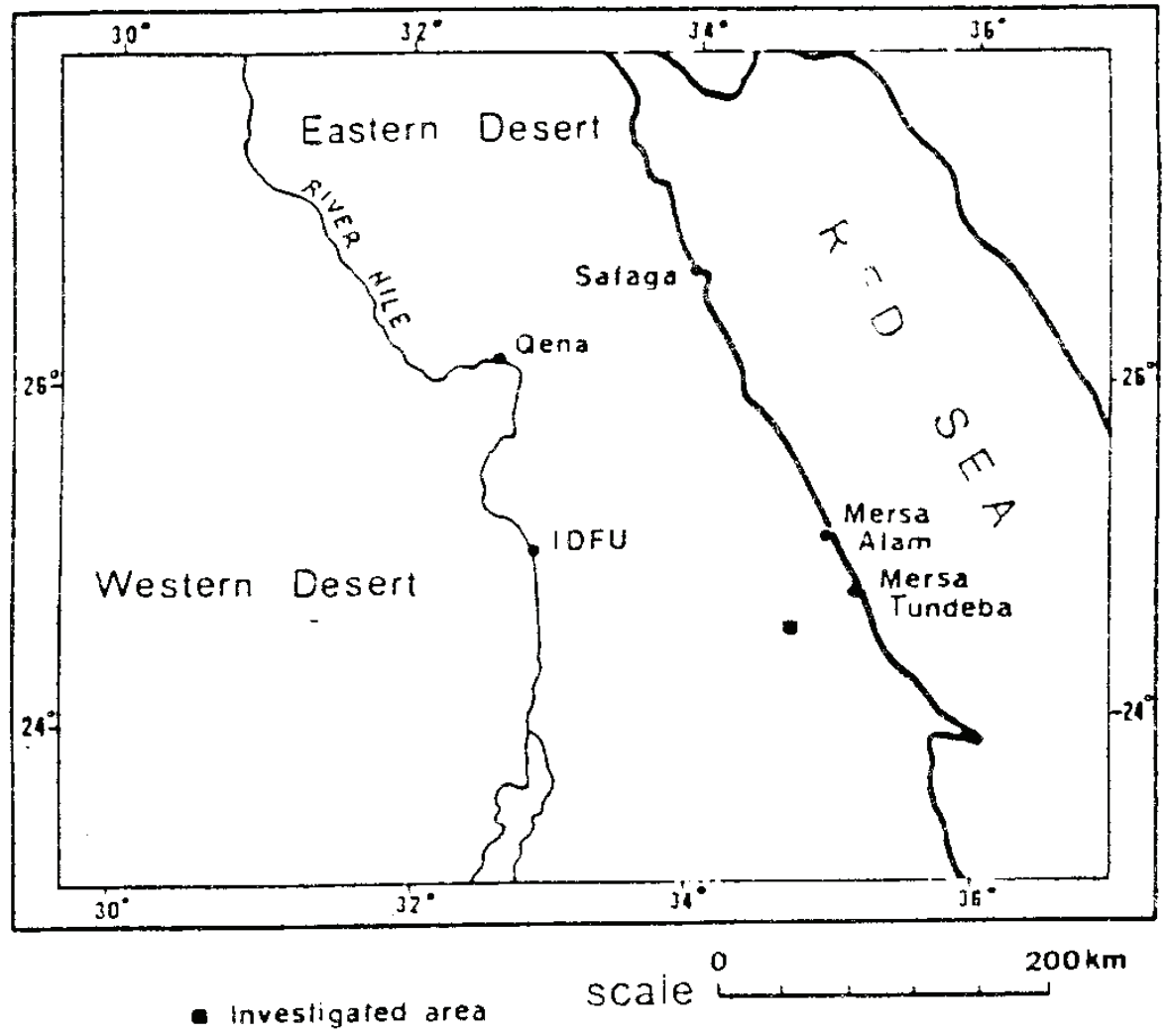

Fig. 1 Location map.

groundmass. Plagioclases are present as fine nematoblastic crystals generally saussuritized, but some xenoblasts may show lamellar twinning. Chlorite is generally interleaved with some fine grained brownish biotite; both are observed wrapping around quartz and plagioclase xenoblasts. Actinolite nematoblasts are pleochroic from light yellowish-green to light green.

Graphitic material occurs as massive aggregates forming stringers and veinlets. Bands rich in the graphitic material may alternate with graphite poor bands.

\subsection{Actinolite-Talc-Chlorite-Graphite Schists}

Actinolite forms generally pale green lepidoblasts, whereas its fibroblasts are occasionally aggregated in bundles. Chlorite lepidoblasts are intermixed with actinolite. Talc may be observed as an alteration product, in addition to its presence forming a dense matrix of scaly aggregates. Rare antigorite was observed in association with the talcose matrix.

Fine-grained graphite and carbonaceous material are generally dispersed in the groundmass and may fill the cracks and cleavage planes of some other minerals (Fig. 2). Massive dense aggregates of graphitic material may occur as patches, streaks and veinlets exhibiting crumbling and microfolding (Fig. 3).

In the polished surfaces of some 15 samples, graphite occurs in both varieties of schists, as fine to medium grained bundles, blades and laths (Fig. 4). It is sometimes bent and crumbled. Graphite exhibits grayish white color, with strong anisotropism and wavy extinction. Bireflectance in graphite is clear, where Rmax in oil ranges from 10 to 14 , for Wadi Lawi graphitic material, which can be compared with that of the semi-graphite to full-ordered graphite mentioned by Diessel and Offler (1975) and Kwieciňska (1980) $[14,15]$.

The most commonly associated opaque mineral is magnetite, which occurs as subhedral medium to fine 


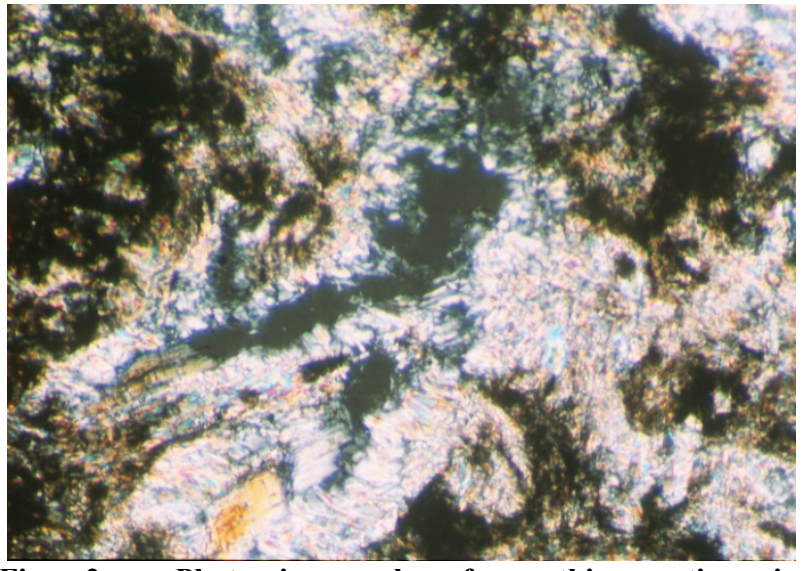

Fig. 2 Photomicrograph of a thin section in graphite-bearing schists, showing graphitic material filling the interstices of the talcose rock. P.P.L. $X=34$.

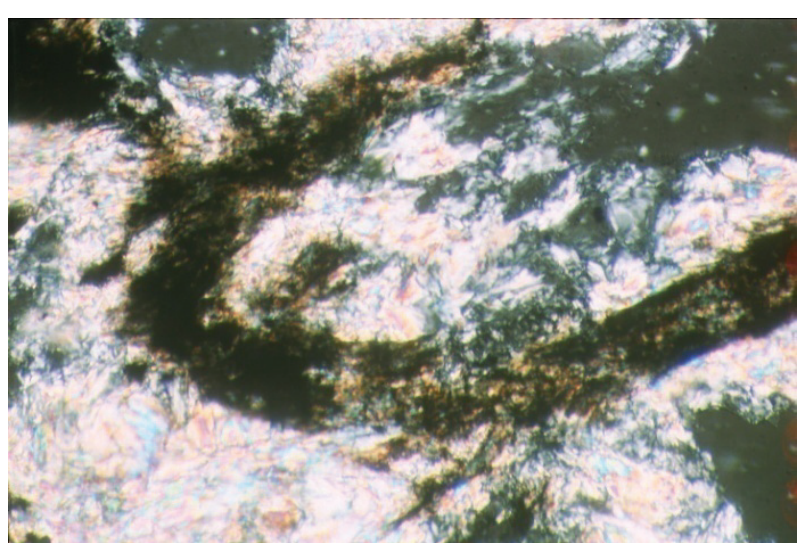

Fig. 3 Photomicrograph of thin section in graphite-bearing schists, showing crumbling of graphite material. C. $\mathrm{P}$. $\mathrm{X}=$ 180.

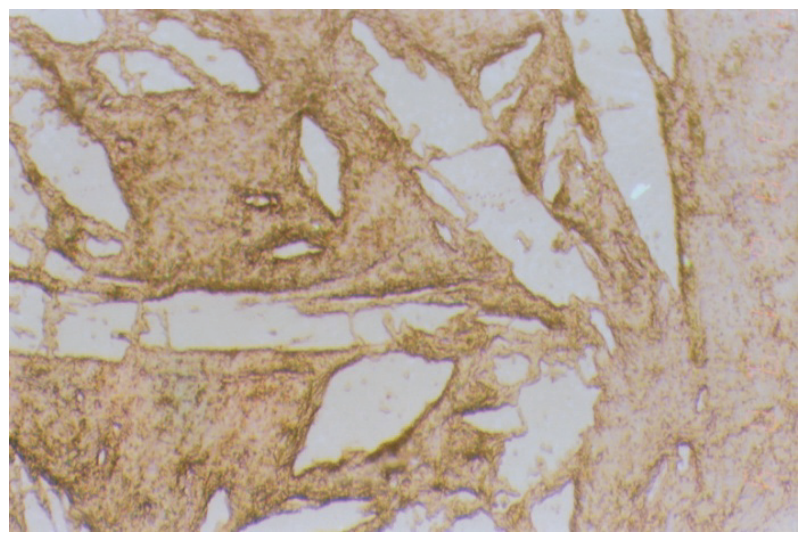

Fig. 4 Photomicrograph of a polished surface in graphite-bearing schists, showing medium to fine grained graphite blades. P.P.L. $X=100$.

grains, forming skeletal aggregates (Fig. 5). Fine grained pyrite is enclosed in graphite (Fig. 6), whereas it is also commonly seen scattered in the gangue. Scarce specks of chalcopyrite noticed.

\section{Graphite Mineralogy}

\subsection{Sample Preparation}

Carbonaceous material was separated from other, acid dissolved materials in three samples of the graphite-bearing Wadi Lawi schists, by the treatment with hot $\mathrm{HF}$ and $\mathrm{HCl}$, following a procedure that does not affect the chemistry and crystal structure of graphite [16-19]. Material passing through a 100 mesh screen, from the crushed graphite-bearing schists, was treated, on a steam path, successively by: (1) hydrochloric acid (1-2 N) for about 2 hours, (2) hydrofluoric acid (55\%) for 8 to 10 hours, (3) hydrochloric acid (4-5 N) for about 6 hours. Steps (2) and (3) were repeated at least twice. In these treatments drying the residue was avoided. After each acid treatment

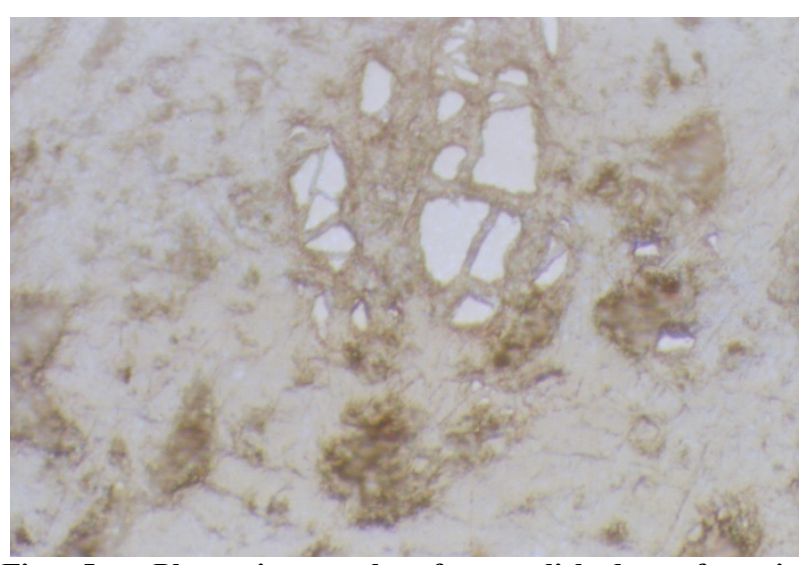

Fig. 5 Photomicrograph of a polished surface in graphite-bearing schists, showing the skeletal aggregates of magnetite P.P.L $X=180$.

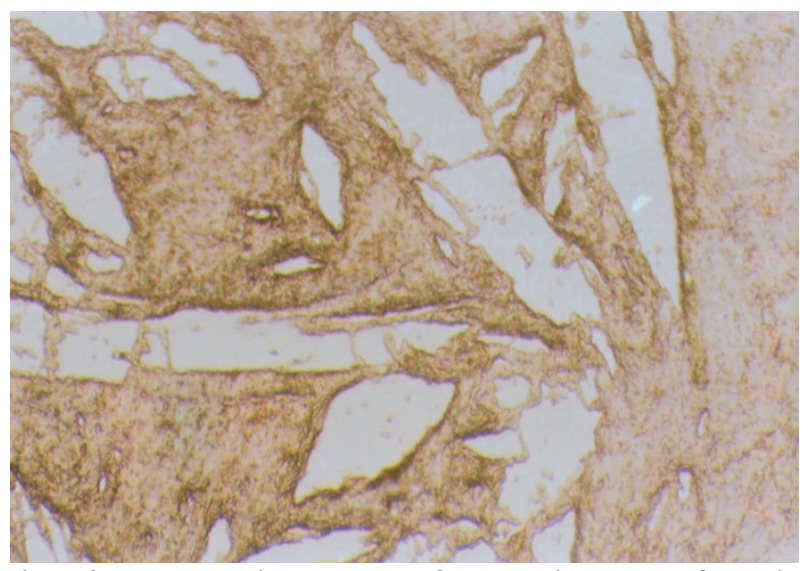

Fig. 6 Photomicrograph of a polished surface in graphite-bearing schists, showing pyrite fine intergrowths in graphite blades. P.P.L. $X=180$. 
the residue was washed by distilled water, but at the final stage of treatment the residue was washed by ethanol. That final residue appeared as a black to dark gray powder. It consists mainly of carbonaceous material and maybe some other insoluble materials such as zircon, pyrite and rutile if they are present in the original rock.

\section{Methods and Techniques}

\subsection{XRD (X-Ray Diffraction)}

The separated graphitic materials from the three investigated samples were sedimented from distilled water on glass slides, and analyzed by SIEMENS $\mathrm{X}$-Ray diffractometer, using Ni-filtered $\mathrm{Cu} \mathrm{K} \alpha$ radiation. Diffractogram was running at a scanning speed $1 \% / \mathrm{min}$, and chart speed $200 \mathrm{~mm} / \mathrm{h}$. XRD investigations were carried out at the Institute of Physics, Silesian University, Katowice, Poland.

\subsection{Electron Microscopy}

The separated graphitic materials were sedimented on copper grids and examined with a Joil-J 500 transmission electron microscope (E.M. Lab, Physics Department, Cairo University). Selected area electron diffraction patterns were obtained with the microscope operating at $80 \mathrm{kV}$.

\subsection{Isotopes Determinations}

For isotopes analyses, $\mathrm{CO}_{2}$ gas was prepared from the separated graphitic material by combustion at $800{ }^{\circ} \mathrm{C}$ in pure oxygen at $1 \mathrm{~atm}$., using $\mathrm{CuO}_{2}$ catalyst. The $\mathrm{CO}_{2}$ was purified by passing through a trap cooled with dry ice, and then it was analyzed using DELTA-C mass spectrometer (Mass Spectrometry, Lab., Institute of physics, A.G.H., Cracow, Poland).

\subsection{DTA (Differential Thermal Analysis)}

The samples for DTA were prepared from finely ground (-200 mesh), previously separated graphitic material. Approximately $0.25 \mathrm{gms}$, were mixed with 0.75 gms of $\mathrm{Al}_{2} \mathrm{O}_{3}$ as a thermally inert substance, these thermal investigations were carried out at TA Lab., Faculty of Earth Sciences, Silesian University, Poland. Heating rate was adjusted to be in the order of $10{ }^{\circ} \mathrm{C}$ per minute, within temperature range of 20 to $1,000{ }^{\circ} \mathrm{C}$. Air was allowed to have free access to the sample during analysis.

\subsection{IR (Infrared) Spectra}

IR spectra were recorded as $\mathrm{K} B r$ discs using PERKIN ELMER 297, 4000-200 $\mathrm{cm}^{-1}$ spectrophotometer, at the Spectrograph Lab., Chemistry Department, Faculty of Science, Menufiya University.

\section{Results}

\subsection{XRD (X-Ray Diffraction)}

Landis (1971) [19] mentioned that the term graphite is used for the fully ordered variety. All sub-graphic carbon can be designated as graphited, and increase in degree of disorder can be expressed in terms of subscript values $\left(d_{1}, d_{2}\right.$ and $\left.d_{3}\right)$. Fully ordered graphite is characterized by a diffraction pattern with an intense, sharp and symmetrical (002) (hexagonal index with I index omitted) reflection at 3.35-3.36 Ả, as well as other considerably weaker reflections (e.g. 100, 101, 004) at higher angels. The decrease of ordering from graphite to graphited is accompanied by: A-The absence of reflections other than (002), B-Broadening and markedly skewing of the (002) peak, and $\mathrm{C}$ - The increase of $\mathrm{d}_{002}$ values up to 3.5-3.75 A for $\mathrm{d}_{2}$ and $\mathrm{d}_{3}$.

XRD patterns for Wadi Lawi graphitic material, and the data concerning the 002 peak extracted from these patterns, compared with those of Landis (1971) (Table 1), show that the graphitic material in sample (39) is compared with the fully ordered graphite. The other two samples (42 and 34) are related to the graphite- $\mathrm{d}_{1}$ of Landis (op.cit.), on the basis of skewing of the (002) peak, in addition to the disappearance of any other reflections other than the (002) on the reflectometer traces of these samples. 
Table 1 XRD data concerning the 002 peak.

\begin{tabular}{lllll}
\hline Reference & $\mathrm{I} / \mathrm{I}_{\mathrm{o}}$ & $\begin{array}{l}\text { Correct } \\
\mathrm{d}_{002} \text { at } \max \end{array}$ & $\begin{array}{l}\text { Height/width } \\
\text { At } 1 / 2 \text { height }\end{array}$ & $\begin{array}{l}\mathrm{d}_{002} \mathrm{~A} \text { at } \\
(1 / 2 \text { width at } 1 / 2 \text { height })\end{array}$ \\
\hline Wadi Lawi & & & & \\
S. No. 39 & 98 & 3.35 & $57^{*}$ & 3.3 \\
S. No. 34 & 4 & 3.35 & 6 & 3.35 \\
S. No. 42 & 4 & 3.35 & 10 & 3.35 \\
Graphite (Landis1971) & & $3.35-3.36$ & 30 & $3.35-3.36$ \\
Fully ordered & - & $3.35-3.36$ & $3-15$ & $3.38-3.41$ \\
Graphite $d_{1}$ & - & $3.37-3.44$ & $3-15$ & ca. 3.40 \\
Graphite $d_{1 \mathrm{~A}}$ & - & &
\end{tabular}

* The reinforcement of this peak with quartz is expected.

The skewed (002) peak presented in the diffractograms of the sample (42\& 34 ), may be attributed to a mixture of slightly ordered graphitic materials (e.g. fully ordered graphite and graphite- $\mathrm{d}_{1}$ ), as mentioned by Landis (op.cit.). Itaya (1981) [18, 19] on the other hand attributed the presence of a combination of both sharp and diffuse peaks in the position of (002) peak, in the X-ray diffractograms of some Japanese graphitic materials extracted from politic schists, to the mixing of the well ordered detrital graphite, with the less ordered carbonaceous material.

\subsection{TEM (Transmission Electron Microscopy)}

Grain size, shape and crystallinity of the separated graphite material, from Wadi Lawi samples, were investigated using the TEM (transmission electron microscope). Nevertheless the coarser flakes are common, reaching up to 8 microns, the particle size of the graphitic material was widely varied (Fig. 7). They exhibit irregular particles with ragged, platy, angular to subrounded outlines, and frequently aggregated.

Electron diffraction patterns were obtained from numerous particles in each sample. Aggregated concentrations may give polycrystalline electron diffraction patterns. Wadi Lawi graphitic samples exhibit two main pattern varieties (Fig. 8):

A-Distinct spot pattern of the diffractional reflexes of the graphite lattice, representing the fully-ordered structure of graphite, and;

B-Ring patterns, which may be with weak superimposed spots corresponding to (100) and (110) reflections, exhibiting lower ordering in graphite.
The occurrences of the two structural states - confirmed by XRD previously mentioned - are comparable with those of Landis (1971), Itaya (1981) and Buseck and Bo-Jun (1985) [18-20]. While Landis (op.cit.) [19] suggest that this is due to the intermixing (inter-layering) of the fully-ordered graphite, with a less ordered variety, Itaya (op. cit.) mentioned that it may be due to the presence of both fully-ordered detrital graphite and metamorphosed carbonaceous material in the same sample, where the sharp reciprocal lattice points observed by Landis could be due to the detrital graphite.

Buseck and Bo-June (1985) [20], considered that the variability of the structures revealed by HRTEM images appears to be the continuous process of graphitization of the carbonaceous material through the progressive metamorphism. They (op. cit.) on another hand attributed that structural heterogeneity to that the precursor materials may have consisted of both graphitized and non-graphitized carbon.

\subsection{Carbon Isotopic Composition}

The results of carbon isotopic composition in Wadi Lawi samples (Table 2), compared with some world averages, are accurate to $1 \pm \%$ and are given in reference to PDB standard for carbon-isotopes and VSMOW standard for O-isotopes [21]. The results are designated as $\delta(\%)$ where:

$$
\delta=\mathrm{R}_{\text {sample }}-\mathrm{R}_{\text {standard }} / \mathrm{R}_{\text {standard }} * 1,000
$$
as: $\mathrm{R}=\mathrm{C}^{13} / \mathrm{C}^{12}$ for carbon, and $\mathrm{R}=\mathrm{O}^{18} / \mathrm{O}^{16}$ for oxygen.

$\delta^{13} \mathrm{C}$ values of Wadi Lawi graphite range from $-22.85 \%$ o to $-23.39 \%$ o with an average $-23.06 \%$, refering 

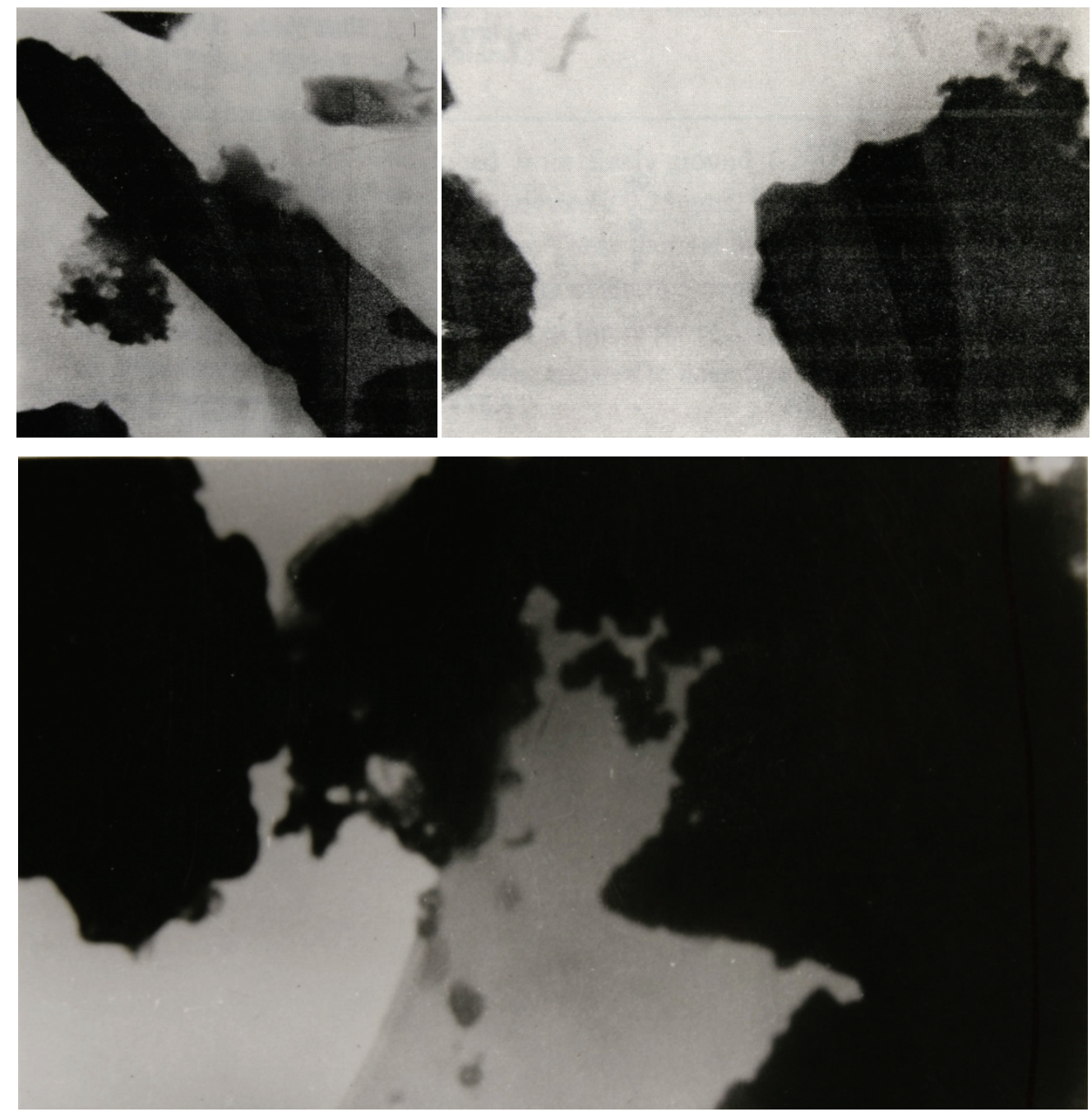

Fig. 7 TEM of the separated graphitic material from wadi Lawi samples.

The variation in size and shape of particles. Well formed, subhedral hexagonal crystallites are evident in the samples. A \& B: from sample (39), and C: from sample (42).

A \& B: $X=2,800$ and $C: X=7,000$.

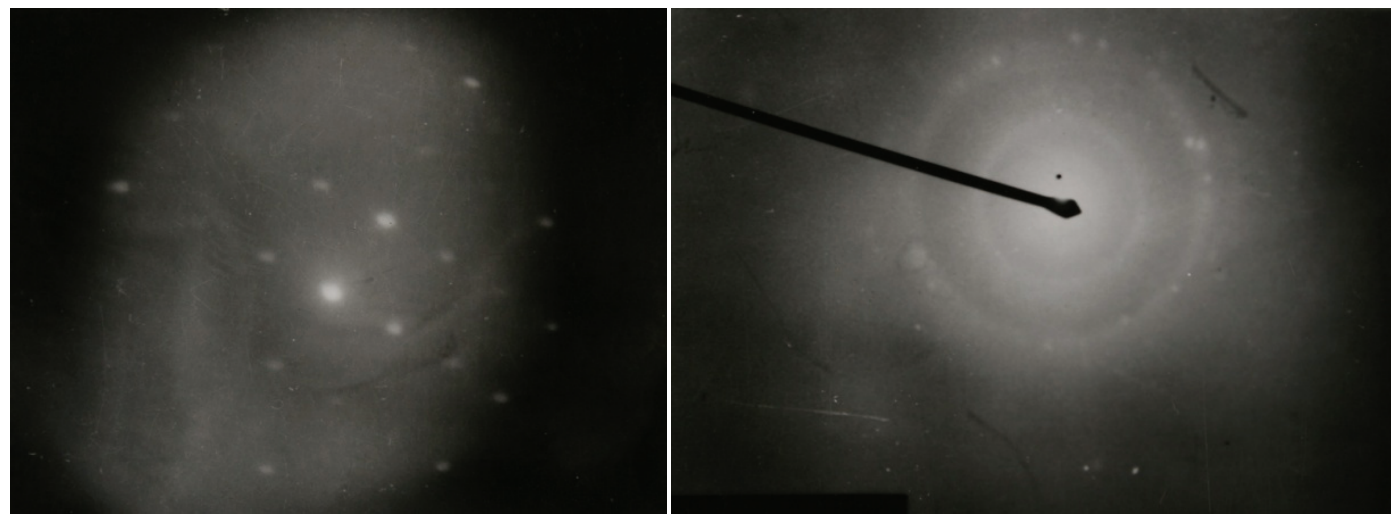

Fig. 8 Electron diffraction patterns obtained from different graphite crystallites.

A: Spot pattern in bright field from well-ordered graphite plate;

B: Ring patterns with weak superimposed spots corresponding to (100) and (110) reflexes , obtained in dark field, from less—ordered graphite plates. 
Table 2 Carbon and oxygen isotopic composition of graphite from Wadi Lawi and some world averages.

\begin{tabular}{lll}
\hline References & $\delta^{13} \mathrm{C}(\mathrm{PDB})$ & $\delta^{18} \mathrm{O}(\mathrm{VSMOW})$ \\
\hline Wadi Lawi graphite & -22.93 & -10.16 \\
S. No. 39 & -22.85 & -14.49 \\
S. No. 23 & -23.39 & -16.49 \\
S. No. 42 & & \\
Kwieciňska (1980) & & -22.20 \\
Graphite in gneisses, phyllites and mica schists (Pninerdo, Italy) & -23.60 & -17.70 \\
Quartz-graphite schist & -27.80 & -20.00 \\
Graphite ore (Witoslowice, Poland) & -21.10 & -19.10 \\
Graphite disseminated in gneisses (Black Donald Mine, Ontario, Canada) & & \\
Weiss et al. (1993) & -21.20 & nd \\
Graphitized coal & & nd \\
Graphite from schists & -21.90 & nd \\
Flake graphite marble & -21.70 & \\
Schrauder et al. (1993) & -3.65 & nd \\
Graphite in gneisses of Elsenreich & & nd \\
Graphite in gneisses of Amstal & -21.50 & -23.15 \\
\hline
\end{tabular}

$\mathrm{nd}=$ not determined.

to an organic protolith for that graphite, whereas graphite $\delta^{13}$ values around $-22 \%$ (PDB) exhibit the isotopic characteristics in silicate rocks and confirm their organogenic origin [22-24]. Schrauder et al. (op.cit.) [24] mentioned also that the small variations of carbon isotopic composition from various localities (which are also included in Table 2) imply that the protoliths were homogeneous in terms of carbon isotopic composition.

In spite of the igneous origin of Wadi Lawi graphite schists [2], graphite organogenic origin is suggested, whereas the juvenile carbon is believed to have $\delta^{13} \mathrm{C}$ value of about $-7 \%$, and if it was derived from magmatic carbon monoxide the $\delta^{13} \mathrm{C}$ of the source gas should have been approximately $-5 \%$ o to $-7 \%$ o [25-28]. In addition to any filtration $\mathrm{CO}_{2}$-rich fluids during metamorphism seems unlikely in view of the presence of low $\delta^{13} \mathrm{C}$ values of graphite [24]. Accordingly, the possibility cannot be eliminated that this graphitic carbon in Wadi Lawi schists is related to post depositional contaminations, which is in agreement with the suggestions of Oehler and Smith (1977) [23], through their investigations of reduction in the early Archean rocks from Isua, Greenland.

$\delta^{18} \mathrm{O}$ (VSMOW) for Wadi Lawi graphite ranges from $-10.16 \%$ o to $-16.49 \%$ with an average of $-13.17 \%$. These values are hardly comparable with the $\delta^{18} \mathrm{O}$ values estimated for graphite separated from metamorphic siliceous rocks. Wadi Lawi graphite $\delta^{18}$ $\mathrm{O}$ values played a good role with those of graphite separated from carbonate bearing rocks (Table 2). Kwieciňska (1980) [29] mentioned that the isotopic composition of oxygen does not show any regularities in the graphites she studied. The present author think that the main reason of that argument, is due to the lack of correct data on the oxygen isotopic composition in graphite separated from siliceous rocks to be compared with.

\subsection{DTA (Differential Thermal Analysis)}

DTA was applied on Wadi Lawi graphite samples to determine their nature and also to define their metamorphic conditions.

In agreement with that previously mentioned by Diessel and Offler (1975), Kwieciňska and Parachoňiak (1976) and Kwieciňska (1980) [14, 15, 29], the DTA curves of Wadi Lawi graphite (Fig. 9) show distinct exothermal effects in the range of 585 to $640{ }^{\circ} \mathrm{C}$, and generally followed by small endothermic reactions. Skewing of these DTA peaks and their relatively low intensity can be interpreted according to Kwieciňska (1980) [15] suggestions that the DTA peaks may show variations in shape and breadth depending on the amount of graphitic substances, 


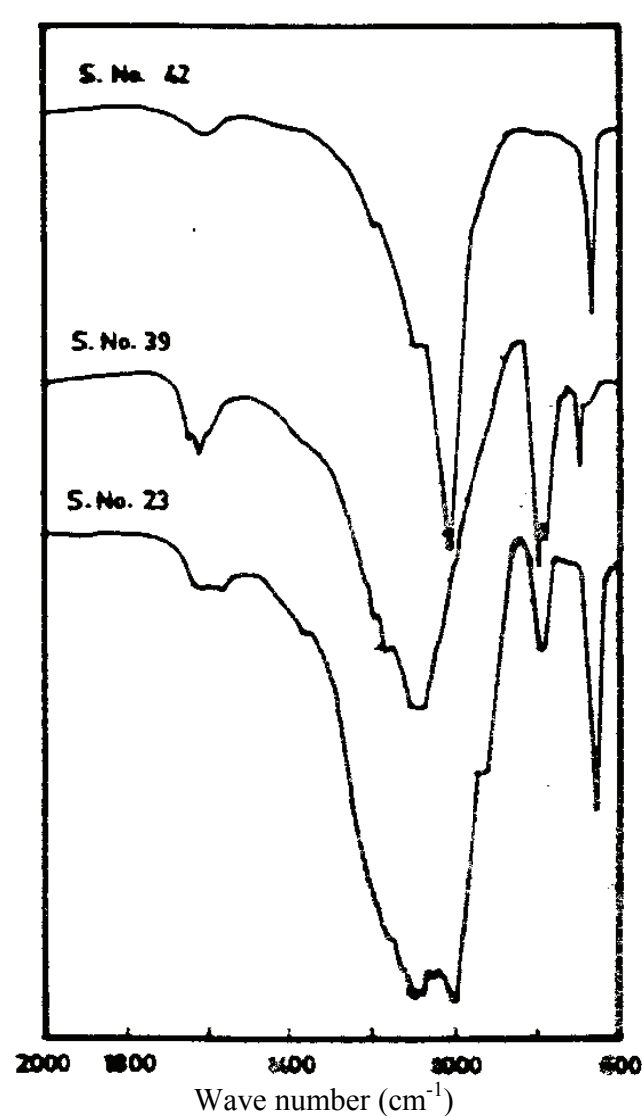

Fig. 9 DTA patterns for graphitic material separated from Wadi Lawi schists Notice; the endothermic peak of the remnant quartz at $570{ }^{\circ} \mathrm{C}$ in sample 39.

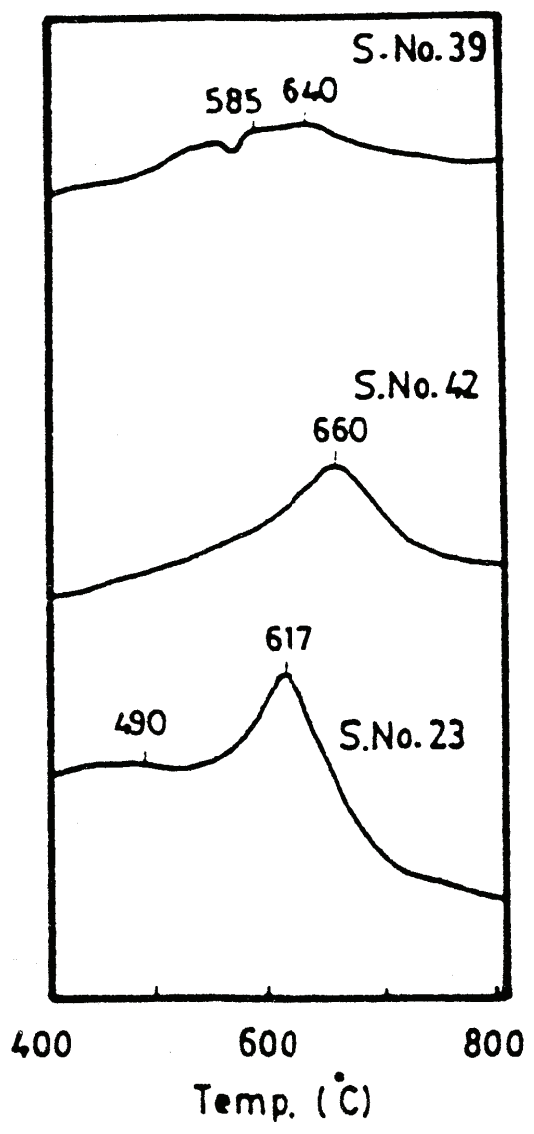

Fig. 10 IR spectra pattern for graphitic material separated from Wadi Lawi schists.

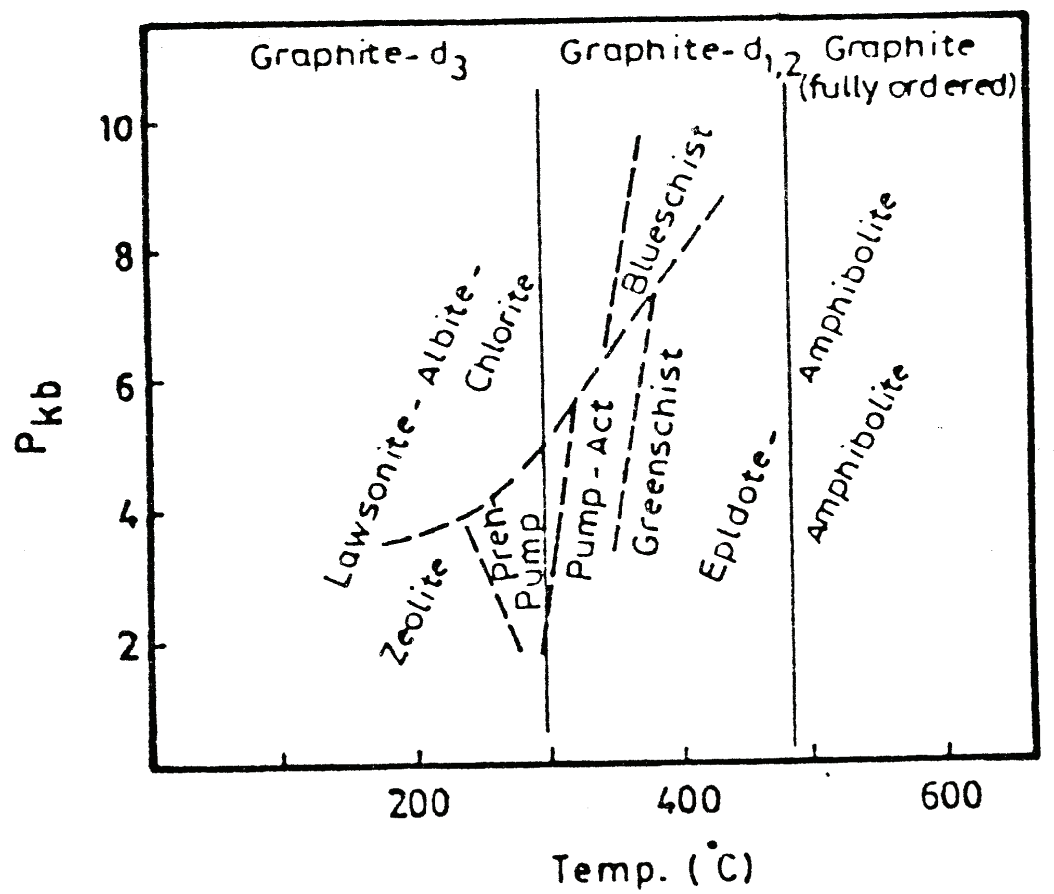

Fig. 11 P-T facies metamorphic grid, showing estimated conditions at which fully-ordered graphite occur in nature. The curve after Landis (1971). 
whereas Diessel and Offler (1975) [14] noted also that there is an increase in both peak width and temperature with increasing metamorphic grade.

The exothermic peaks exhibited by Wadi Lawi graphite (Fig. 10) can be attributed to graphite intermixed with semi-graphite, which had been formed under the conditions of the greenschist facies to the lower amphibolite facies [14, 15, 29].

\subsection{IR (Infrared) Spectra}

The chemical structure of the separated graphic material from Wadi Lawi samples was investigated by IR spectroscopy, where Fig. 10 shows several bands appearing in all of the detected samples, ranging from 580 to $990 \mathrm{~cm}^{-1}$. These bands are characteristic for the out of plane bending for the aromatic hydrocarbons [30], which confirm the organogenic origin of these graphitic materials.

\section{Discussion and Conclusions}

The mineralogy of the graphitic materials in the graphite-bearing schists of Wadi Lawi shows that they range from semi-graphite (graphite- $\mathrm{d}_{1}$ ) to graphite (full-ordered graphite). Nevertheless, no detailed study concerning the origin of graphite is yet available, the isotopic composition, the DTA and IR of the present work graphite, compared with other world graphitic materials [14, 15, 22-24, 29] refer to organic protoliths for Wadi Lawi graphitic materials.

The possibility that Wadi Lawi graphitic carbon is related to post depositional contaminations - from the nearby Wadi Ghadir and Wadi Lawi old politic sediments, occurring now as greywacks $[1,2$, 10] — can be suggested as compared with Oehler and Smith (1977) [23].

In this regard, post-depositional contamination by biogenic material has been noted also as one explanation of a similar correlation between low concentration and light isotopic composition of graphitic carbon in Lunar basalts [31].

XRD and DTA investigations can reveal that the graphitic material is formed under conditions of the greenschist facies [14, 15, 17-19, 23, 29].

It is also suggested according to Landis (1971) [19] as in Fig. 11, in addition to Grew (1974) [17], estimations for the temperature of the first appearance of layered ordering in graphite $\left(300\right.$ to $500{ }^{\circ} \mathrm{C}$ at a pressure of $3 \mathrm{kP}$ or more) - that the temperature of graphite formation in Wadi Lawi ranges from 400 to $600{ }^{\circ} \mathrm{C}$ in a pressure range of 4 to $6 \mathrm{kP}$.

\section{References}

[1] Basta, F. 1983. "Geology and Geochemistry of Ophiolitic méLange and Other Rock Unites in the Area West of Gabal Ghadir, Eastern Desert, Egypt.” Ph.D. thesis, Cairo University.

[2] Bishady, A. M., Attia, M. S., Hathout, M. H., and Omar, M. I. B. 1994. "Petrography and Geochemistry of the Ophiolitic Mélange in the Area of Wadi Lawi and Wadi Lawawi, South Eastern Desert, Egypt." Archiwum Mineralogiczne, Poland 2: 69-96.

[3] El Bayoumi, R. M. 1980. "Ophiolites and Associated Rocks of Wadi Ghadir, East of Gabal Zabara, Eastern Desert, Egypt.” Ph.D. Thesis, Cairo University, Egypt.

[4] Ries, A. C., Shakleton, R. M., Graham, R. H., and Fitches, W. R. 1983. "Pan-African Structures, Ophiolites and Mélange in the Eastern Desert of Egypt: A New Traverse at $26^{\circ}$ N." J. Geol. Soc. 140: 75-95.

[5] Schrauder, M., Beran, A., Hoern, S. S., and Richter, W. 1993. "Constraints on the Origin and the Genesis of Graphite-Bearing Rocks from the Variegated Sequence of the Bohemian Massif (Austria)." Mineral. Petrol. 49: 175-200.

[6] Azer, N. 1966. "Remarks on the Origin of Precambrian Mineral Deposits in Egypt." Tschem. Min. Petr. Mitt. 13: 1-2.

[7] El Zoghby, M. E. 1953. "The Mineral Resources of Egypt." Speciasl Print.

[8] Hume, W. F. 1936. "Geology of Egypt. V. II, part III.” Geol. Surv., Egypt.

[9] Shakleton, R. M., Ries, A. C., Graham, R. H., and Fitches, W. R. 1980. "Pan-African Ophiolitic Mélange in the Egyptian Eastern Desert.” Nature 285: 472-4.

[10] Sabet, A. H., and Zaatout, M. A. 1955. "Geology of El-Shalul, El-Bakria District, Barramiya West Sheet." Geol. Surv. Egypt.

[11] Hilmy, M. E. 1960. "On the Mineralogy of Some Graphite Occurrences in the Eastern Desert, Egypt." Egypt. Sci. Fed., 4th Sci. Sess., p. 313. (In Arabic). 
[12] Anwar, Y., and Kotb, H. 1968. "Studies on the Graphite of Wadi Sitra, Eastern Desert, Egypt." Bull. Fac. Sci. Alexandria 5 (7): 361-72.

[13] El Hinnawi, E. E., Kabesh, M. L., and Bishady, A. M. 1973. "Mineralogy and Geochemistry of Egyptian Graphite Schists." Chem. Erde. Bull. 32: 135-62.

[14] Diessel, C. F. K., and Offler, R. 1973. "Change in Physical Properties of Coalified and Graphitized Phytoclasis with Grade of Metamorphism.” N. Jb. Miner. H. 1: 11-26.

[15] Kwieciňska, B. 1980. "Mineralogy of Natural Graphitees." In Prace Mineralogiczne, pp. 67, 73.

[16] French, B. M. 1964. "Graphitization of Organic Material in a Progressively Metamorphosed Precambrian Iron Formation." Science 146: 917-8.

[17] Grew, E. S. 1974. "Carbonaceous Material in Some Metamorphic Rocks of New England and Other Areas." $J$. Geol. 82: 50-73.

[18] Itaya, T. 1981. "Carbonaceous Material in Politic Schists of the Sanbagawa Metamorphic Belt in Central Shikoku, Japan." Lithos 14: 215-24.

[19] Landis, C. A. 1971. "Graphitization of Dispersed Carbonaceous Material in Metamorphic Rocks." Cont. Miner. Petrol. 3: 34-45.

[20] Buseck, P. R., and Bo-Jun. 1985, "Conversion of Carbonaceous Material to Graphite during Metamorphism." Geochem. Et Cosmochem. Acta 49: 2003-16.

[21] Craig, H. 1953. "The Geochemistry of the Stable Carbon Isotopes." Geochem. et Cosmochem. Acta 3: 53.

[22] Hoefs, J. 1987. Stable Isotope Geochemistry. Berlin:
Springer Verlag.

[23] Oehler, D. Z., and Smith, I. W. 1977. "Isotopic Composition of Reduced and Oxidized Carbon in Early Archean Rocks from Isua, Greenland." Precambrian Research 5: 221-8.

[24] Sabet, A. H. 1981. "Geology and Mineral Deposits of Gebel El-Sibai Area, Red Sea Hills, Egypt.” Ph. D. Thesis, I.T.C. Delfet, Holand.

[25] Degens, E. T. 1969. "Geochemistry of Stable Isotopes.” In Organic Geochemistry, edited by G. Eglinton and M. T. Murphy. Berlin: Springer Verlag.

[26] Deines, P., and Gold, D. P. 1960. "The Change in Carbon and Oxygen Isotopic Composition during Contact Metamorphism of Trenton Limestone by the Mount Royal pluton." Geochem. et Cosmochem. Acta 33: 421-4.

[27] Vinegradov, A. B., and Kropotova, O. L. 1988. "The Isotopic Formation of Carbon in Geologic Processes." Intel. Geol. Rev. 9110: 497-506.

[28] Weis, P. L., Friedman, I., and Gleason, J. P. 1981. "The Origin of Epigenetic Graphite: Evidence from Isotopes." Geochem. et Cosmochem. Acta, V. 45: 2325-32.

[29] Kwieciňska, B., and Barachoňiak, W. 1976. "Thermal Investigations of Graphiticsubstances from Metamorphic Rocks." Mineralogia Polonica 7 (2).

[30] Pavia, D. L., Lambman, J. M., and Kriz, J. R. 1979. Spectroscopy, Sndudars College, Philidelphia, U.S.A., p. 299.

[31] Kaplan, I. R., and Smith, J. W. 1970. "Concentration and Isotopic Composition of Carbon and Sulfur in Apollo II Lunar Samples." Science 167: 541-3. 